\title{
A Comparative Study on Morphemes of English, French and Chinese
}

\author{
Guoqiang Cui \\ PhD candidate; Full-time lecturer of School of Foreign Languages, Jilin University of Finance and \\ Economics, Jingyue Street, Jingyue District, Changchun, Jilin Province, P.R.China, 130117 \\ cuiguoqiang123@126.com
}

Keywords: Comparative study; Morphemes; Relations; Distinctions

\begin{abstract}
Though English belongs to the Germanic group of languages; French is a branch of Roman languages that derived from Latin; Chinese is in the department of Asian-African languages, many Chinese are learning all of them. Morpheme is the smallest semantic unit in languages. It is essential and decisive in language learning and understanding. Therefore, the thesis engages in initially discussing the relationship and distinction of morphemes among English, French and Chinese. It facilitates the simultaneous learning of three languages.
\end{abstract}

\section{Why Morphemes?}

Respectively belonging to Germanic, Roman and Asian-African language group, English, French and Chinese are all hot languages around the world. Many English words come from French. Besides, English is the globally acknowledged official language, which helps the popularization of English in China. English and French have precise definition of tense, such as the present tense and the past tense, so they are morphological languages, for example:

He will work in the garden / Il travaillera dans le jardin. (The future tense)

He worked in the garden / Il a travaillé dans le jardin. (The past tense)

Though some scholars think in Chinese we have similar tense expressions, for example, we may use 'Zhe' to signify progressive tense, and we may refer to the past tense by applying 'Le', sometimes there may be vagueness and incorrectness, Chinese is a non-morphological language, e.g.:

Ta Zai Kan Zhe Ni. (Present progressive tense)

Ta Chi Le. (Past tense)

however, Tai Shang Zuo Zhe Zhu Xi Tuan. (A kind of state, but not tense)

Tian Hen Re, Rang Wo Men "Kai Zhe Chuang Hu Shui Jiao" or "Kai Le Chuang Hu Shui Jiao". ("Zhe" and "Le" contain similar meaning)

Chinese linguists never applied the rules of 'tense' and 'form'. In this case, it will be difficult for us to learn them comparatively, especially the associations. But each language has its own morpheme, which is basic but decisive to language learning and distinguishing meaning. To learn the three different languages well, it is quite necessary for us to discuss the relations and distinctions of morphemes of English, French and Chinese.

\section{The Relations and Distinctions of Morphemes in Three Languages}

"Language is composed of pronunciation, vocabulary and grammar. Pronunciation has both natural and social quality. The natural quality is within the scope of physics and physiology, and the latter attributes to phonemics".[1] Though phoneme plays an important role in distinguishing meaning, it contains no meaning itself. The language elements making sense in communication are combinations of sound and meaning. Our communicational language is made up of words. A word can be further divided into morphemes, either one or more. A morpheme is the smallest linguistic unit that has semantic meaning (the minimal combination of sound and meaning. [2] 
In spoken language, morphemes are composed of phonemes (the smallest linguistically distinctive units of sound), and in written language morphemes are composed of graphemes (the smallest units of written language).[3]

In all the three languages, there are words made up by one or more morphemes. (See table 1)

Table 1

\begin{tabular}{|c|c|c|c|}
\hline $\begin{array}{c}\text { langue } \\
\text { morpheme }\end{array}$ & English & French & Chinese \\
\hline One morpheme & boy & lente & Ren \\
\hline Two morphemes & boyfriend & lentement & Ren Qing \\
\hline
\end{tabular}

The Root Morphemes \& Additive Morphemes. According to the differences in meaning and word structure, morphemes can be classified into root morpheme and additive morpheme, which are abbreviated as root and affix. Both of root and affix don't hold grammatical sense, hence, they won't bring grammatical changes to sentences or remarks.

Of root morphemes: Root morpheme is not only the foundation of word structure, but also the essential element in the formation of meaning. It is the core of word. Root morpheme can be a word independently, as well can function as a part of a compound word, for exact examples, see table 2 below:

Table 2

\begin{tabular}{|c|c|c|l|}
\hline $\begin{array}{c}\text { langue } \\
\text { word type }\end{array}$ & English & French & \multicolumn{1}{|c|}{ Chinese } \\
\hline Root words & boy \& friend; man \& date & bon \& jour & $\begin{array}{l}\text { Mai and Mai; Pu Tao and } \\
\text { Tang }\end{array}$ \\
\hline Compound word & boyfriend and mandate & bonjour & Mai Mai; Pu Tao Tang \\
\hline
\end{tabular}

As mentioned in table 2, both 'boy' and 'friend' are foundations of 'boyfriend'; in addition, they are the points where meaning starts. Likewise, the French roots 'bon' and 'jour' also have the same functions.

Of additive morphemes: Additive morphemes are named "affix" in short. The affixes that signify lexical sense in additive morphemes can be classified into prefix, infix and suffix.

In the book Morphology, Francis states "In English words like misunderstanding, coexist, dislike and foretell, mis-, co-, dis-, and fore- are representatives of prefix";[4] in Chinese, word-building prefix like "Lao" in "Lao Shu" and "Lao Li" may broaden Chinese vocabulary as well; French words also have prefixes. For example, un- in unconnue means 'not', re- in recommencer refers to 'again' and bon- in bonsoir is 'good'. All the new words don't carry grammatical features. The only difference is that French prefixes don't change the words' part of speech, but not the case in English and Chinese. See table 3:

Table 3

\begin{tabular}{|l|l|l|c|c|}
\hline & Words & Prefixes & New words & Change in Part of Speech \\
\hline French & connue & un & unconnue & Adjective-—Adjective \\
\hline English & large & en & enlarge & Adjective-—-Verb \\
\hline Chinese & San & Chu & Chu San & Number-—Noun \\
\hline
\end{tabular}

From the table, we may easily find that the prefixes "en" and "Chu" change adjective "large" to a verb and number "San" to a noun. 
As for infix, it is inserted in the middle of a word, and tears the original word apart. We can only find infixes in Chinese, but not quite often. For example, we may insert "Qi Ba" to "Luan Zao", and "Li Ba" in "Hu Li Ba Tu". In English and French, there are not infixes.

All of the three languages have plenty of suffixes, which are placed at the back of roots, especially English. For example, the noun suffixes including -age, -ance, -ation, -ence, -er, -gram, -graph, -let, -ment and -ship, etc; the adjective suffixes like -able, -al, -ed, -ent, -ible and -ful; adverb suffixes -ally and -fully and verb suffixes -en and -ize, etc. Most of the Chinese noun suffixes have substantive meaning, such as "Shu" in "Mi Shu" and "Wen Shu", but there are also suffixes don" carry substantive meaning, like "Zi" in "Fang Zi", "Piao Zi" and "Dao Zi"; the typical verb suffixes in Chinese are "Le, Zhe, Guo, Yu and Hua", the related examples are "Kan Le Shu", "Zai Yu" and "Lv Hua"; in Chinese, there are adjective suffixes made up by overlapping affixes, such as "Hong Tong Tong", "Lv You You" and "Nao Honghong", which are used for emphasis. Because of the strict logic and form of French, compared with English and Chinese, French seems to have less but stable suffixes. For example, the transformation from adjectives to adverbs will always need suffix 'ment' and the present participle form must have suffix 'ant' after the root. The other suffixes in French seem to have less regularity.

The Free Morphemes \& Bound Morphemes. As many morphemes cannot stand as words on their own, in his book Lexical Semantics, the famous German linguist, Wolfgang Fleischer states that "morphemes should be classified into free morphemes and bound morphemes".[5] That is to say, a morpheme is free if it can stand alone, or bound if it is used exclusively alongside a free morpheme.

Of free morphemes: The usage of free morphemes in English and French are identical. English and French free morphemes, more exactly speaking, the content morpheme or full morpheme is similar to the Chinese morphemes which can either be a word independently or make up a word together with other morphemes. Such as "trust" and "worthy" in English, "bon" and "jour" in French, in addition, "Ren" and "Min" in Chinese, each of them can function as a single word, but they may work together and create new words "trustworthy", "bonjour" and "Ren Min".

In spite of the similar usage, the Chinese free morpheme is a totally different thing from that of English and French. Unlike "Ren" in "Ren Min" and "Shui" in "Shui Jing", Chinese free morphemes refer to the morphemes which could only be applied independently, such as "A", "Ne", "Ma" and "En". They cannot develop new words with other morphemes. In some degree, Chinese free morphemes are just like the empty morpheme or form morpheme in English and French free morphemes. The empty or form morpheme consists of article, preposition and conjunction. Though they are necessary to sentence structure, they are senseless. In another word, we may say though they are independent words, they seem like to function as bound morphemes. Therefore, we may say "The cats are noisy tonight." or "Cats are often noisy at night." But we never say "The are noisy tonight." Table 4 shows some basic examples of free morphemes in three languages:

Table 4

\begin{tabular}{|l|c|l|c|}
\hline & Example Words & Free Morphemes & Bound Morphemes \\
\hline English & teacher, mistake & teach, take & er, mis \\
\hline French & télécommunication & communication & télé \\
\hline Chinese & - & A, Ne, Ma & Zheng Zhi, Kai Guan \\
\hline
\end{tabular}

Of bound morphemes: A bound morpheme must be used together with a free morpheme. It displays the words' additional or grammatical sense.[6] Bound morphemes can be further divided to derivational morpheme and inflectional morpheme.

The former is of great lexical significance, because it may build plenty of new words. Let's take English for example, when we add -er to "teach", new word "teacher" comes into being; when we add 
super- to marché in French, new word 'supermarché' turns up; the similar expression also exists in Chinese. If we add "Jia" to "Zheng Zhi", it becomes a person.

The latter is of grammatical significance and it may be called "grammatical ending" as well, because it refers to the change in number (singular and plural), gender, tense case and degree (comparative and superlative). For more details and examples of inflectional morphemes in these three languages, see table 5 below:

Table 5

\begin{tabular}{|c|c|c|c|}
\hline $\begin{array}{l}\text { items } \\
\text { langue }\end{array}$ & English & French & Chinese \\
\hline Number & $\begin{array}{l}\text { a book-books, } \\
\text { a painting-paintings }\end{array}$ & $\begin{array}{l}\text { un bain-des bains, } \\
\text { un Chinois-des Chinois }\end{array}$ & $\begin{array}{l}\text { Hai Zi-Hai Zi Men } \\
\text { Lao Shi_Lao Shi Men }\end{array}$ \\
\hline Gender & $\begin{array}{l}\text { the teacher } \\
\text { (for both man or woman) }\end{array}$ & $\begin{array}{l}\text { un Chinois (male) } \\
\text { une Chinoise (female) }\end{array}$ & $\begin{array}{l}\text { Lao Shi } \\
\text { (Either male or female) }\end{array}$ \\
\hline Case & their-theirs & leur-leurs & -— \\
\hline Degree & $\begin{array}{l}\text { long-longer-longest(except } \\
\text { multisyllable \& special } \\
\text { words ) }\end{array}$ & - & -— \\
\hline Tense & I go-She goes & J'enseigne- Tu enseignes & -— \\
\hline
\end{tabular}

Another important point worth mentioning is that some morphemes, such as "cran" and "huckle" can only be used with "berry" hence create "cranberry" and "huckleberry". Such morphemes play the same function as phonemes, which only distinguish meaning instead of implying meaning; in Chinese, "Pi" in "Pi Jiu", "Ka" in "Ka Che" and "Qi Lin" in "Bing Qi Lin" are quite similar usages;[7] as for French, "vélo" in "vélomoteur" is also a good example.

\section{An Important Inspiration----"Splinters"}

In English language, the word "splinters" refers to the basic form of a word.[8] In French, the word "écharde" or "éclat" contains the similar meaning. Though there is no specific and corresponding definition to the word in Chinese, according to the features of morphemes in three different languages, language learners should take good advantage of splinters like '-ash', 'gl-' and '-ump' in English. 'gl-' originally refers to 'the rotary movement of eyes' and it also implies 'sight'. So words contain 'gl-' must have related symbolic sense, such as glare, glance, glimpse and glint; besides, '-ump' refers to 'the round object', so plump, rump and stump has related meaning; 'ash-' symbolizes loud and destructive actions, so it'll be quite easy for us to imagine what crash, flash, slash, smash and splash mean.[9] In French, 'télé' means 'of electricity', therefore, we can easily recognize télécommunication, téléphone and télévision. Such splinters in English and French are just like the 'radicals' in Chinese. In Chinese, "He" means "seed" and "Mi" refers to "rice", so words like "Zhong, Yang, Sui, Zi, Kang, Zhou, Liang and Gao" all have something to do with cereal. If language learners can make well use of these important morphemes, they will absolutely benefit a lot.

\section{Conclusion}

Morpheme is the dominant part in morphology, word, sentence, communication or even a language.[10] A morpheme may be defined as the minimal linguistic sign, a grammatical unit, in which there is an arbitrary union of a sound and a meaning, and which cannot be further analyzed. For English, French and Chinese learners, it will be quite significant to understand the relations and distinctions among the three languages. The thesis tries to make clear as many details by exampling types of morphemes and the interplay of three different languages. 


\section{References}

[1] Lyons, John. Language and Linguistics. Cambridge: Cambridge University Press, 2011.

[2] Shaofang, Wang, Yi, Zhao. "Characteristics of Morpheme and Phoneme between English and German”. Journal of Shenyang University. Vol. 16, No. 3 (Jun. 2004): 88-90.

[3] Rule, George. The Study of Language (2nd edition) [M]. Beijing: Foreign Language Teaching and Research Press, 2000.

[4] Matamba, Francis. Morphology. New York: St. Martin's Press, 1993.

[5] Wolfgang, Fleischer. Lexical Semantics. Berlin: Berlin Press, 1999.

[6] $\mathrm{Xu}$, Yulong. An Introduction to Comparative Linguistics. Shanghai: Foreign Language Educational Press, 1992.

[7] Shuxin, Liu. Chinese Descriptive Lexicon [M]. Beijing: Commercial Press, 2005.

[8] Hui, Yang. "The comparison of morpheme, affix and grammatical ending in English and Chinese", Songliao Journal (Humanities and Social Sciences Edition, 2001), 3, pp.74-76.

[9] Yanan, Han. “A Pilot Study on Morphemes and Affix” [J]. Anhui Literature, 2014 [10].

[10] Hu, Zhuanglin. Linguistics: An Advanced Course Book. Beijing: Peking University Press, 2002. 